\title{
Incidence of common opportunistic infections among HIV-infected children on ART at Debre Markos referral hospital, Northwest Ethiopia: a retrospective cohort study
}

Mamaru Wubale Melkamu', Mulugeta Tesfa Gebeyehu², Abebe Dilie Afenigus², Yitbarek Tenaw Hibstie Belisty Temesgen', Pammla Petrucka ${ }^{3,4}$ and Animut Alebel ${ }^{2,5^{*}}$ (i)

\begin{abstract}
Background: Opportunistic infections (Ols) are the leading cause of morbidity and mortality among children living with human immunodeficiency virus (HIV). For better treatments and interventions, current and up-to-date information concerning occurrence of opportunistic infections in HIV-infected children is crucial. However, studies regarding the incidence of common opportunistic infections in HIV-infected children in Ethiopia are very limited. Hence, this study aimed to determine the incidence of opportunistic infections among HIV-infected children on antiretroviral therapy (ART) at Debre Markos Referral Hospital.
\end{abstract}

Methods: A facility-based retrospective cohort study was undertaken at Debre Markos Referral Hospital for the period of January 1, 2005 to March 31, 2019. A total of 408 HIV-infected children receiving ART were included. Data from HIV-infected children charts were extracted using a data extraction form adapted from ART entry and followup forms. Data were entered using Epi-data ${ }^{\mathrm{TM}}$ Version 3.1 and analyzed using Stata ${ }^{\mathrm{TM}}$ Version 14. The Kaplan Meier survival curve was used to estimate the opportunistic infections free survival time. Both bi-variable and multivariable Cox proportional hazard models were fitted to identify the predictors of opportunistic infections.

Results: This study included the records of 408 HIV-infected children-initiated ART between the periods of January 1, 2005 to March 31, 2019. The overall incidence rate of opportunistic infections during the follow-up time was 9.7 (95\% Cl: $8.13,11.48)$ per 100 child-years of observation. Tuberculosis at $29.8 \%$ was the most commonly encountered Ol at follow-up. Children presenting with advanced disease stage (III and IV) (AHR: 1.8, 95\% Cl: 1.2, 2.7), having "fair" or "poor" ART adherence (AHR: 2.6, 95\% Cl: 1.8, 3.8), not taking Ol prophylaxis (AHR:1.6, 95\% Cl: 1.1, 2.4), and CD4 count or \% below the threshold (AHR:1.7, 95\% Cl: 1.1, 2.6) were at a higher risk of developing opportunistic infections.

Conclusions: In this study, the incidence rate of opportunistic infections among HIV-infected children remained high. Concerning predictors, such as advanced disease stage (III and IV), CD4 count or \% below the threshold, "fair" or "poor" ART adherence, and not taking past Ol prophylaxis were found to be significantly associated with Ols.

Keywords: Anti-retroviral therapy, Children, HIV, Opportunistic infections, Ethiopia

\footnotetext{
* Correspondence: animut.a23@gmail.com

${ }^{2}$ College of Health Science, Debre Markos University, Debre Markos, Ethiopia

${ }^{5}$ Faculty of Health, University of Technology Sydney, Sydney, Australia

Full list of author information is available at the end of the article
}

(c) The Author(s). 2020 Open Access This article is distributed under the terms of the Creative Commons Attribution 4.0 International License (http://creativecommons.org/licenses/by/4.0/), which permits unrestricted use, distribution, and reproduction in any medium, provided you give appropriate credit to the original author(s) and the source, provide a link to the Creative Commons license, and indicate if changes were made. The Creative Commons Public Domain Dedication waiver (http://creativecommons.org/publicdomain/zero/1.0/) applies to the data made available in this article, unless otherwise stated. 


\section{Background}

The epidemic of Human Immunodeficiency Virus (HIV) remains a serious public health concern [1]. In 2018, an estimated 37.9 million people globally were living with HIV, including 1.7 million children (aged < 15 years) [2]. Sub-Saharan Africa (SSA) is the most affected region [3] with Ethiopia ranking within the top 25 countries with the highest new HIV-infection rates [4]. Opportunistic infections (OIs) are infections, which occur more frequently and severely among individuals with weakened immune systems, including People Living with Human Immunodeficiency Virus (PLHIV) [5]. All HIV-infected people are susceptible to develop a wide range of OIs [6], but prevalence and incidence of HIV-associated OIs vary widely $[7,8]$. Most reports on the magnitude of OIs in HIV-infected children are from North America and Europe; while, in SSA, the true burden of OIs among HIV-children remains poorly documented [9] .

OIs are the leading causes of morbidity and mortality among HIV-infected children contributing to $94.1 \%$ of HIV-related deaths [10-13]. Unless OIs are treated as early as possible, they markedly affecting the treatment outcomes of PLHIV leading to poor quality of life, hastening disease progression, increasing medical costs, potentiating the risk of treatment failure, and impairing patient's response to antiretroviral therapy (ART) drugs $[14,15]$. In low and middle income countries, the most frequently occurring OIs are tuberculosis (TB), oral candidiasis, varicella zoster, pneumocystis pneumonia, bacterial pneumonia, herpes zoster, and dermatophyte infections [16, 17].

The World Health Organization (WHO) recommends a range of medical interventions to reduce the occurrence of OIs among PLHIV. These interventions include reduction of exposure, chemoprophylaxis (primary/secondary), immunization, and early initiation of ART [18]. The use of highly active antiretroviral therapy (HAART) has been effective in reducing OIs significantly among children and adolescents infected with HIV [19]. In Ethiopia, the Ministry of Health (MOH) has been implementing different interventions to improve the survival of HIV infected individuals which is reflected, in part, in the increased ART coverage from 5\% in 2010 to $9.5 \%$ in $2013[18,20]$.

Despite the dramatic decline in the incidence OIs after the introduction HAART, they remain a major cause of morbidity and mortality among these vulnerable population [21]. Most HIV-associated OIs and other comorbidities are easily preventable and treatable with safe and cost-effective interventions. However, for better interventions, information regarding the patterns and occurrences of OIs is essential for all age groups (especially vulnerable populations such as children and pregnant women), but are often absent for low and middle income countries, including Ethiopia. Therefore, this study was undertaken to determine the incidence of common OIs among HIV-infected children at Debre Markos Hospital. Results obtained from this study will potentially help health professionals to develop a new strategy for the prevention and management of OIs and inform a national program of research inclusive of interventional studies.

\section{Methods \\ Study design, setting, and period}

A facility-based retrospective cohort study was conducted at Debre Markos Referral Hospital. Debre Markos town is located $300 \mathrm{~km}$ far from Addis Ababa, the capital city of Ethiopia and $265 \mathrm{~km}$ far from Bahir Dar, the capital city of Amhara Region. According to the 2007 national census, Debre Markos has a total population of 62,497 , of whom 29,921 were men and 32,576 were women [22]. Debre Markos Referral Hospital is the only referral hospital in East Gojjam Zone providing services for more than 3.5 million peoples in the zone and neighboring zones. The hospital has been providing HIV-care and ART follow-up services since 2005. Currently, the ART clinic of this hospital has one medical doctor, five nurses, three data clerks, one porter, one cleaner, five case managers, and six adherence supporters. The hospital uses standardized ART monitoring and evaluation tools adapted from the Ethiopian national comprehensive HIV care and treatment guidelines [18]. To date, a total of 466 HIV-infected children commenced ART at this site of which, approximately 350 HIV-infected children are receiving active ART followup at the time of this study.

\section{Study participants}

The source population for this study were all HIVinfected children (aged $<15$ years) ever initiated on ART at Debre Markos Referral Hospital, with the study population including those HIV-infected children started on ART between January 1, 2005 to March 31, 2019. HIVinfected children who had incomplete baseline information (CD4 count, hemoglobin level, WHO clinical stage, weight and height) and/or who had OIs at the time of ART initiation were excluded from the study.

\section{Sampling procedures}

The records of all HIV-infected children ever started on ART (466) at Debre Markos Referral Hospital were recruited. After excluding incomplete records, records of 408 HIV-infected children met the criteria and were included in the study. Data were extracted from the charts of 408 HIV-infected children on ART. 


\section{Variables of the study}

The dependent variable for this study was the occurrence of any type of opportunistic infections during follow-up. The independent variables included: Socio-demographic characteristics (i.e., age, sex, residence, religion, marital status of care giver, relationship of care giver, current status of parents, occupation of the caregiver, and family size); Clinical and laboratory predictors (i.e., WHO clinical stage, CD4 count, hemoglobin (Hgb) level, underweight, wasting, stunting, history of Prevention of Mother to Child Transmission (PMTCT), prior history of OIs, functional status, and developmental status); and ART and other medication-related predictors (i.e., past OI prophylaxis, type of baseline ART regimen, ART eligibility criteria, presence of regimen changed, level of ART adherence, ever taking Isoniazid Preventive Therapy (IPT), ART side effects, and ART treatment failure).

\section{Operational definition of variables}

In this study, an event was considered when HIVinfected child developed any form of OIs after ART initiation during the follow-up period.

Censored was recorded when HIV-infected children dropped or transfer out (whether dead or alive) to other health institutions or are still on active ART follow-up, but did not develop any OIs by the end of the study.

ART adherence was classified as good, fair, or poor, according to the percentage of drug dosage calculated from the total monthly dose of ART drugs. Good was reported with compliance equal to or greater than $95 \%$ or $\leq 3$ missed doses per month; fair reflected 85-94\% compliance and between 4 and 8 missing doses per month); and poor reflected less than $85 \%$ compliance or $\geq 9$ missed dose per month) [23].

Child developmental status was classified as appropriate (able to attain milestones for age), delayed (failure to attain milestones for age); and regression (loss of what has been attained for age) [18].

Children with weight/age Z-score $<-2 \mathrm{SD}$, height/age $\mathrm{Z}$-score $<-2 \mathrm{SD}$, and weight/height Z-score $<-2 \mathrm{SD}$ were considered to be underweight, stunted, and wasted respectively [24, 25].

OIs are infections, which occur more frequently and severely among individuals with weakened immune systems, including People Living with Human Immunodeficiency Virus (PLHIV) [5]. According to the Ethiopian ART guidelines, the common OIs include herpes zoster, bacterial pneumonia, pulmonary $\mathrm{TB}$, extra-pulmonary $\mathrm{TB}$, oral candidiasis, oesophageal candidiasis, mouth ulcer, diarrhoea, pneumocystis pneumonia, central nervous system toxoplasmosis, Cryptococcal meningitis, non-Hodgkins lymphoma, Kaposi's sarcoma, cervical cancer, and others [18].
CD4 counts or percentage (\%) below the threshold was considered if the child had CD4 cell counts $<1500 /$ $\mathrm{mm}^{3}$ or $25 \%$ for age $<12$ months, CD 4 cell counts $<750 /$ $\mathrm{mm}^{3}$ or $<20 \%$ for age $12-35$ months, CD 4 cell counts $<$ $350 / \mathrm{mm}^{3}$ or $<15 \%$ for age $36-59$ months, and CD4 cell counts $<200 / \mathrm{mm}^{3}$ or $<15 \%$ for age $\geq 60$ months [26].

\section{Data collection procedures and quality assurance}

The data extraction form was based on the federal Ministry of Health's HIV-care/ART follow-up and intake forms, which are used in the ART clinics of Ethiopian hospitals. The data extraction form included the following variables: socio-demographic characteristics, ART and other medication, clinical, and laboratory-related information. Data were collected by three BSc prepared nurses working in the ART clinic of Debre Markos Referral Hospital. To assure data quality, a data extraction checklist was carefully adapted from a standardized ART intake and follow up forms, nurses currently work in the ART clinic and who took ART training were recruited as data collectors, a one-day training was given for both data collectors and supervisors, completeness of the recorded variables were double checked by taking some randomly selected cards, and the supervisor as well as principal investigators carefully monitored the entire data collection process. Subsequently, all relevant data were retrieved through reviewing of HIV-infected children's cards. The occurrence of OIs during data extraction was ascertained by reviewing the health professionals' reporting on patient charts. Any laboratory tests obtained at the time of ART initiation were considered as a baseline data. However, if laboratory tests were not done during ART initiation, any lab tests done within a month of ART initiation were considered as the baseline.

\section{Data analysis}

Before entry, data were checked for its completeness and consistency. We used Epi-data ${ }^{\mathrm{Tm}}$ Version 3.1 for data entry and STATA ${ }^{\mathrm{Tu}}$ Version 14 for data analysis. Besides, Emergency Nutritional Assessment (ENA) and WHO AnthroPlus software were used to analyze the nutritional status (underweight [WAZ], stunting [HAZ] and wasting [WHZ]) of HIV-infected children. Descriptive statistics were summarized as percentage, mean, and median, and visualized using tables and charts. The OIs free survival time was estimated using the Kaplan-Meier survival curve. Besides, the OIs free survival time between different categorical explanatory variables were compared using generalized log rank test. A life table was constructed to estimate probabilities of OIs at different time intervals and cumulative survival probabilities. The common assumptions of Cox proportional hazard regression model were checked using Schoenfeld residuals test. In the bi-variable analysis, variables with $p$-values $\leq 0.25$ 
were selected for the multivariable analysis $[27,28]$. In the final model, variables with $p$-values $<0.05$ were considered as statistically significant predictors of OIs.

\section{Results}

Socio-demographic characteristics of the cohort

A total of 466 HIV-infected children's medical records were retrieved. Of these, 58 were excluded from the analysis due to incompleteness. The remaining 408 HIVinfected children on ART were included in this study. The median age of the study participants was 7 years $(\mathrm{IQR}=4$, 10). About $42.9 \%$ of the children were in the age group of 5 to 9 years. Slightly more than half $(54.7 \%)$ of the children were male, and more than two thirds (72.1\%) were from urban areas. More than half (53.7\%) of the parents were both alive and the majority (85.3\%) of children were living with their biological parents (Table 1).

Clinical, laboratory and medication-related characteristics About half (51.9\%) of children were classified as WHO clinical stage I and II and almost two third (67.9\%) of the children had CD4 counts or percentage (\%) above the threshold. About $10.3 \%$ of participants had $<10 \mathrm{mg} /$ $\mathrm{dl}$ hemoglobin level with a median of 12.3 (IQR $=11.3-$ 13.3) $\mathrm{mg} / \mathrm{dl}$, with $49.3,23.8$, and $51.7 \%$ of participants being underweight, wasted and stunted respectively. More than half $(60.8 \%)$ of children had taken past OI prophylaxis. Children exhibiting a good adherence level to ART and nevirapine baseline ART regimens were 78.7 and $66.7 \%$, respectively and $56.1 \%$ had no history of PMTCT (Table 2).

\section{Incidence of opportunistic infections during follow-up}

The study participants were followed for a minimum of 2 months and a maximum of 132 months. The total person months of the cohort was 16, 024 child-months of observation. During the follow-up time, almost one third (31.6\%) of the study participants developed OIs. This study found that the incidence rate of OIs among HIVinfected children was 9.7 (95\% CI: 8.1, 11.5) per 100 childyears of observation. From all types of OIs occurring during the follow-up time, TB (29.8\%) was the most common, followed by bacterial pneumonia (27.7\%), and nonHodgkins lymphoma or Kaposi's sarcoma (11.3\%) (Fig. 1).

Table 1 Sociodemographic characteristics of HIV-infected children on ART at Debre Markos Referral Hospital, Northwest Ethiopia, from January 1, 2005 to March 31, 2019 ( $N=408)$

\begin{tabular}{|c|c|c|c|}
\hline Characteristics & Category & Frequency (N) & Percentage (\%) \\
\hline \multirow[t]{3}{*}{ Age of the child (years) } & $0-4$ years & 122 & 29.9 \\
\hline & $5-9$ years & 175 & 42.9 \\
\hline & $10-14$ years & 111 & 27.2 \\
\hline \multirow[t]{2}{*}{ Sex } & Male & 223 & 54.7 \\
\hline & Female & 185 & 45.3 \\
\hline \multirow[t]{2}{*}{ Residence } & Urban & 294 & 72.1 \\
\hline & Rural & 114 & 27.9 \\
\hline \multirow[t]{3}{*}{ Family size } & $1-3$ & 184 & 45.1 \\
\hline & $\geq 4$ & 179 & 43.9 \\
\hline & Not recorded & 45 & 11.0 \\
\hline \multirow[t]{2}{*}{ Current status of parents } & Both alive & 219 & 53.7 \\
\hline & One or both deceased & 189 & 46.3 \\
\hline \multirow[t]{3}{*}{ Marital status of the caregiver } & Married & 172 & 42.0 \\
\hline & Divorced/ widowed & 167 & 41.0 \\
\hline & Not recorded & 69 & 17.0 \\
\hline \multirow[t]{4}{*}{ Occupation of the caregiver } & Employed & 86 & 21.3 \\
\hline & Unemployed & 203 & 50.3 \\
\hline & Merchant & 65 & 16.1 \\
\hline & Not recorded & 54 & 12.4 \\
\hline \multirow[t]{2}{*}{ With whom the child lives } & Biological & 348 & 85.3 \\
\hline & Non-biological & 60 & 14.7 \\
\hline \multirow[t]{3}{*}{ Religion } & Orthodox & 348 & 85.3 \\
\hline & Muslim & 21 & 5.1 \\
\hline & Others & 39 & 9.5 \\
\hline
\end{tabular}


Table 2 Baseline clinical, laboratory and medication-related characteristics of the HIV-infected children on ART at Debre-Markos Referral Hospital, Northwest Ethiopia, from January 1, 2005 to March 31, 2019 (N=408)

\begin{tabular}{|c|c|c|c|}
\hline Characteristics & Categories & Frequency (N) & Percentage (\%) \\
\hline \multirow[t]{3}{*}{ History of PMTCT } & Yes & 56 & 13.7 \\
\hline & No & 229 & 56.1 \\
\hline & Not recorded & 123 & 30.2 \\
\hline \multirow[t]{2}{*}{ History of Ols } & Yes & 215 & 52.7 \\
\hline & No & 193 & 47.3 \\
\hline \multirow[t]{2}{*}{ Weight for age } & Normal & 207 & 50.7 \\
\hline & Underweight & 201 & 49.3 \\
\hline \multirow[t]{2}{*}{ Weight for height } & Normal & 311 & 76.2 \\
\hline & Wasted & 97 & 23.8 \\
\hline \multirow[t]{2}{*}{ Height for age } & Normal & 197 & 48.3 \\
\hline & Stunted & 211 & 51.7 \\
\hline \multirow[t]{2}{*}{ WHO clinical stage } & Stage I and II & 212 & 52.0 \\
\hline & Stage III and IV & 196 & 48.0 \\
\hline \multirow[t]{2}{*}{ CD4 counts or $\%$} & Above the threshold & 277 & 67.9 \\
\hline & Below the thresheold & 131 & 32.1 \\
\hline \multirow[t]{2}{*}{ Hgb level } & $\geq 10 \mathrm{~g} / \mathrm{dl}$ & 366 & 89.7 \\
\hline & $<10 \mathrm{~g} / \mathrm{dl}$ & 42 & 10.3 \\
\hline \multirow[t]{2}{*}{ ART eligibility criteria } & Test and treat & 67 & 16.4 \\
\hline & CD4 or WHO staging & 341 & 83.6 \\
\hline \multirow[t]{3}{*}{ Type of regimen at baseline } & Nevirapine base & 272 & 66.7 \\
\hline & Efaveraze base & 86 & 21.1 \\
\hline & Protease inhibitor base & 50 & 12.3 \\
\hline \multirow[t]{2}{*}{ Ever taking IPT } & Yes & 217 & 53.2 \\
\hline & No & 191 & 46.8 \\
\hline \multirow[t]{2}{*}{ ART adherence } & Good & 321 & 78.7 \\
\hline & Fair/ poor & 87 & 21.3 \\
\hline \multirow[t]{2}{*}{ Past Ol prophylaxis } & Yes & 248 & 60.8 \\
\hline & No & 160 & 39.2 \\
\hline \multirow[t]{2}{*}{ ART side effect } & Yes & 19 & 4.7 \\
\hline & No & 389 & 95.3 \\
\hline \multirow[t]{2}{*}{ Regimen change } & Yes & 84 & 20.6 \\
\hline & No & 324 & 79.4 \\
\hline \multirow[t]{2}{*}{ Treatment failure } & Yes & 20 & 4.9 \\
\hline & No & 388 & 95.1 \\
\hline \multirow[t]{3}{*}{ Functional status } & Working & 153 & 53.3 \\
\hline & Ambulatory & 113 & 39.4 \\
\hline & Bed ridden & 21 & 7.3 \\
\hline \multirow[t]{3}{*}{ Developmental status } & Appropriate & 73 & 60.3 \\
\hline & Delayed & 41 & 33.9 \\
\hline & Regressed & 7 & 5.8 \\
\hline
\end{tabular}


Opportunistic infections free survival time of HIV-infected children on ART

In this study, the median OIs-free survival time was 103 months (IQR $=30,128)$. Additionally, children presenting with WHO clinical stage III and IV during ART initiation had less OIs free survival time when compared to children presenting in WHO stages I and II (Fig. 2). Figure 3 shows that the OIs free survival time of children presenting with severe immunodeficiency (CD4 count or \%bellow the threshold) was lower than those children with mild immunodeficiency (CD4 count or \% above the threshold). Moreover, children who had "fair or poor" ART drug adherence had less OIs free survival time as compared to those who had good ART drug adherence (Fig. 4). Furthermore, children who did not take past OI prophylaxis had less OIs free survival time as compared to the past OI prophylaxis user cohort (Fig. 5).

\section{Predictors of Ols among HIV-infected children on ART}

Weight for age Z-scores, history of past OIs, Hgb levels, WHO clinical staging, CD4 counts or \%, taking past OI prophylaxis, ever taking IPT, and ART drug adherence were variables for multivariable analysis Of these, WHO clinical staging, CD4 counts, ART drug adherence, and past OIs prophylaxis were found to be significant predictors of OIs. Children presenting with WHO clinical stage III and IV were nearly 2 times (AHR (adjusted hazard ratio): 1.8, 95\% CI: 1.2, 2.7) more likely to develop OIs as compared to those children in WHO clinical stages I and II. This study also found that HIV-infected children on ART who had "fair" or "poor" ART adherence were 2 and half fold (AHR: 2.6, 95\% CI: $1.8,3.8$ ) more likely to develop OIs as compared to those children who had "good" ART adherence. The risk of developing OIs among children with CD4 count or \% below the threshold was 1.7 times (AHR: 1.7, 95\% CI: 1.1, 2.6) higher as compared to those children with CD4 counts or \% above the threshold. Lastly, the risk of developing OIs among children who did not previously take OI prophylaxis was 1.6 times (AHR: 1.6, 95\% CI: 1.1, 2.4) higher to those who took past OI prophylaxis (Table 3).

\section{Discussion}

This facility-based retrospective cohort study was undertaken to determine the incidence of common OIs among HIV-infected children on ART at Debre Markos Referral Hospital. Almost one third (31.6\%) of the study participants developed OIs, yielding an incidence rate of OIs 9.7 (95\% CI: 8.1, 11.5) per 100 child-years of observation. This finding is comparable with an Asian-based study reporting 10.5 per 100 person-years [21]. Similarly, our finding is much higher than studies from the United States of America (4.99 per 100 person-years) [29], Latin America (1.1 per 100 person-years) [30], and Brazil (2.63 per 100 person-years) [10].

Literature also showed that HIV-related OIs remain high in resource limited settings; especially with SSA being disproportionately affected [9]. Developed countries have advanced technologies for early diagnosis, prevention, and

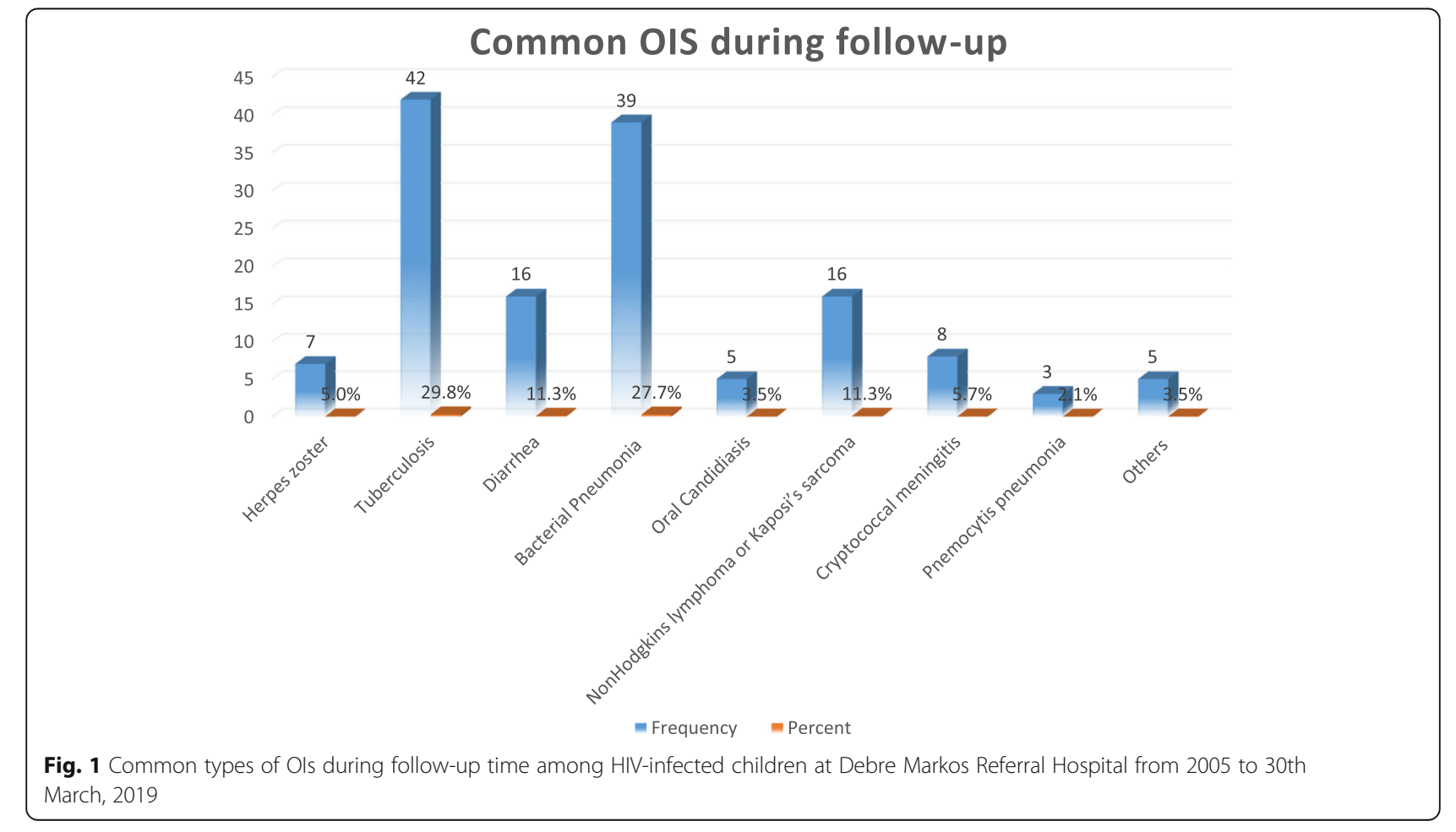




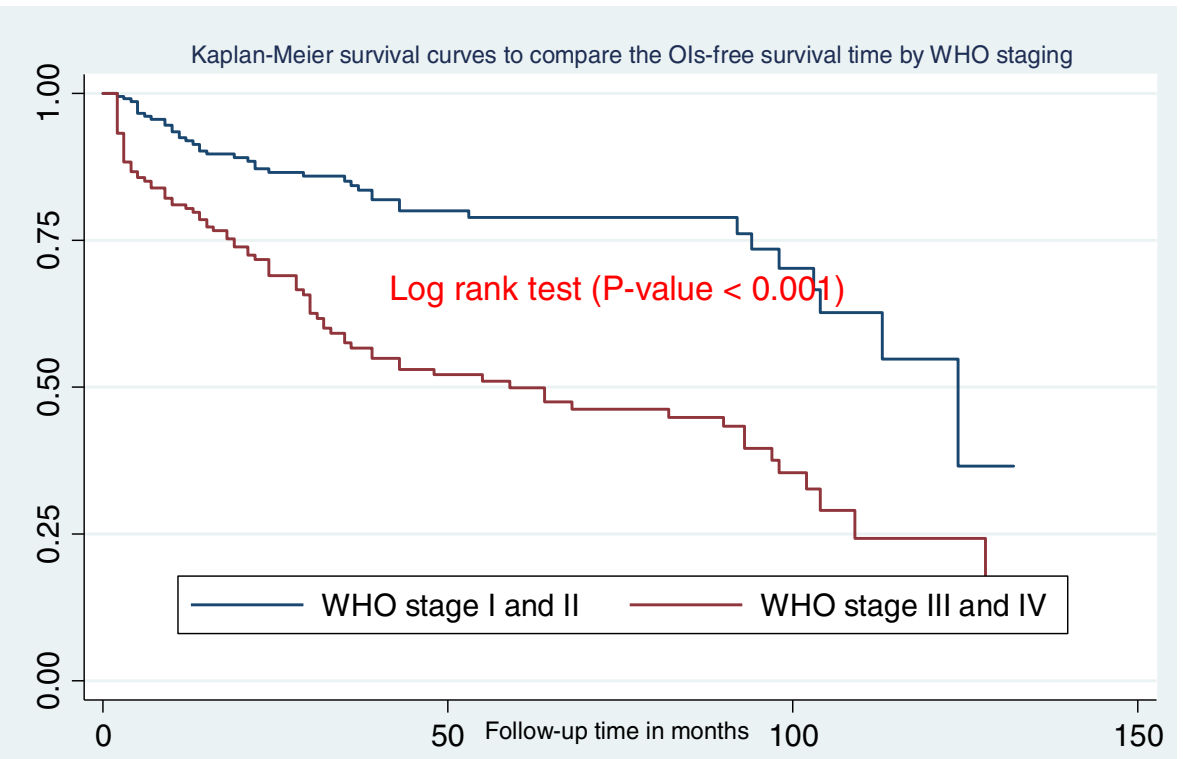

Fig. 2 Kaplan-Meier survival curves to compare the Ols-free survival time of HIV-infected children on ART with different categories of WHO clinical stages at Debre-Markos Referral Hospital from 2005 to 30th March, 2019

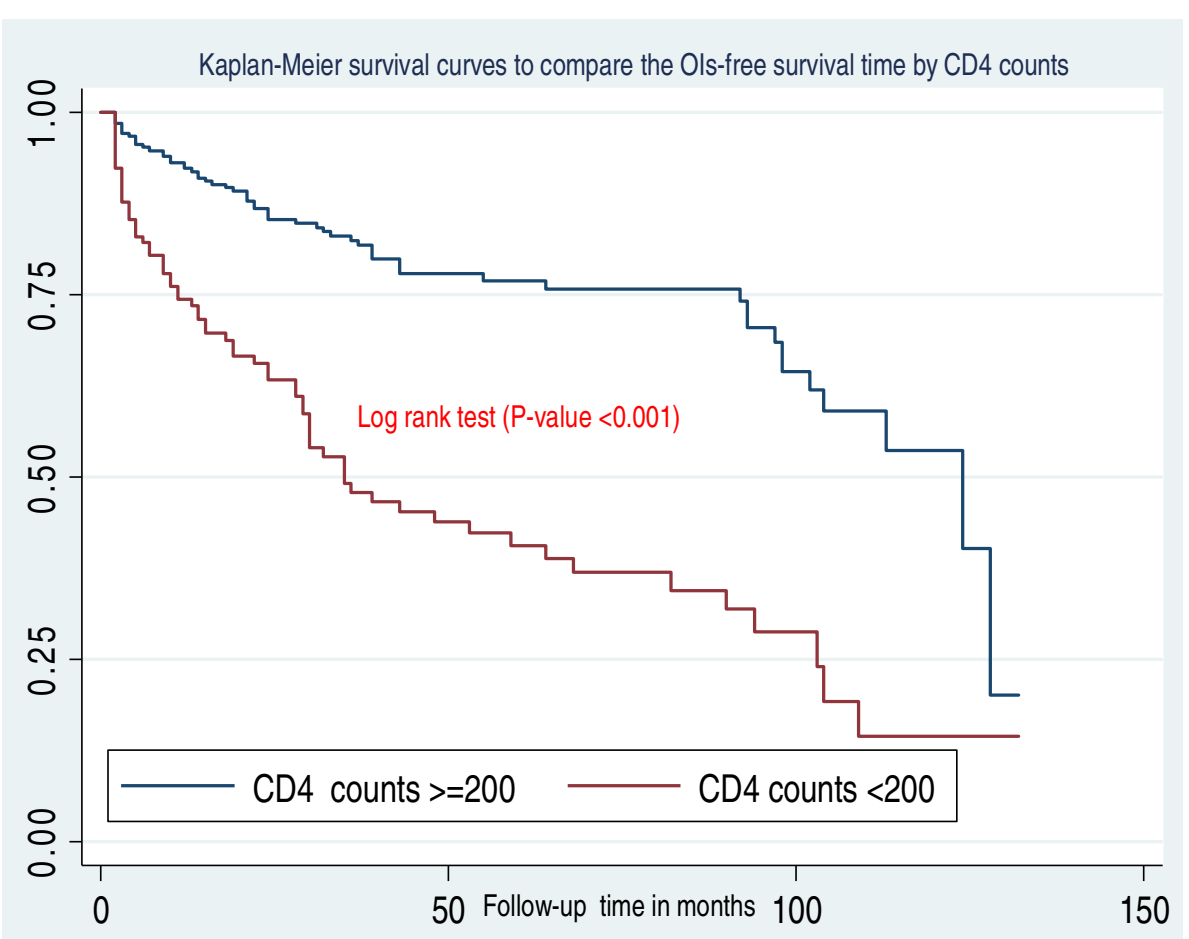

Fig. 3 Kaplan-Meier survival curves to compare the Ols-free survival time of HIV-infected children on ART with different categories of CD4 counts or \% at Debre-Markos Referral Hospital from 2005 to 30th March, 2019 


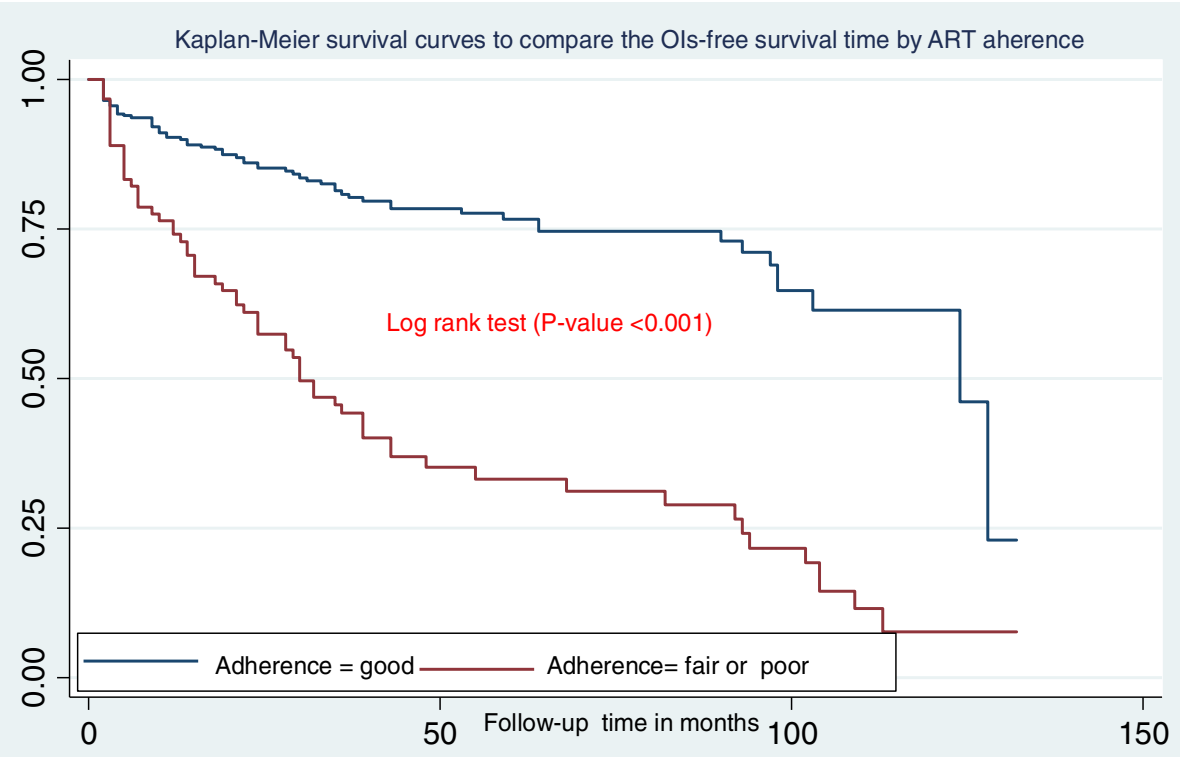

Fig. 4 Kaplan-Meier survival curves to compare the Ols-free survival time of HIV-infected children on ART with different categories of ART drug adherence at Debre-Markos Referral Hospital from 2005 to 30th March, 2019

management of OIs. Additional explanations for the above noted discrepancies might be attributed to the lack of awareness among HIV-infected peoples living in developing countries to take ART medications and OIs prophylaxis continuously [31]. Poverty, overcrowding, and malnutrition are common problems in developing countries, which could contribute to the higher occurrence of OIs among HIV-infected people.

Among all types of OIs, TB is the most common (29.8\%) during the follow-up time. This finding is consistent with a study conducted in India, which documented that $\mathrm{TB}$ is the most (34.6\%) commonly diagnosed OI

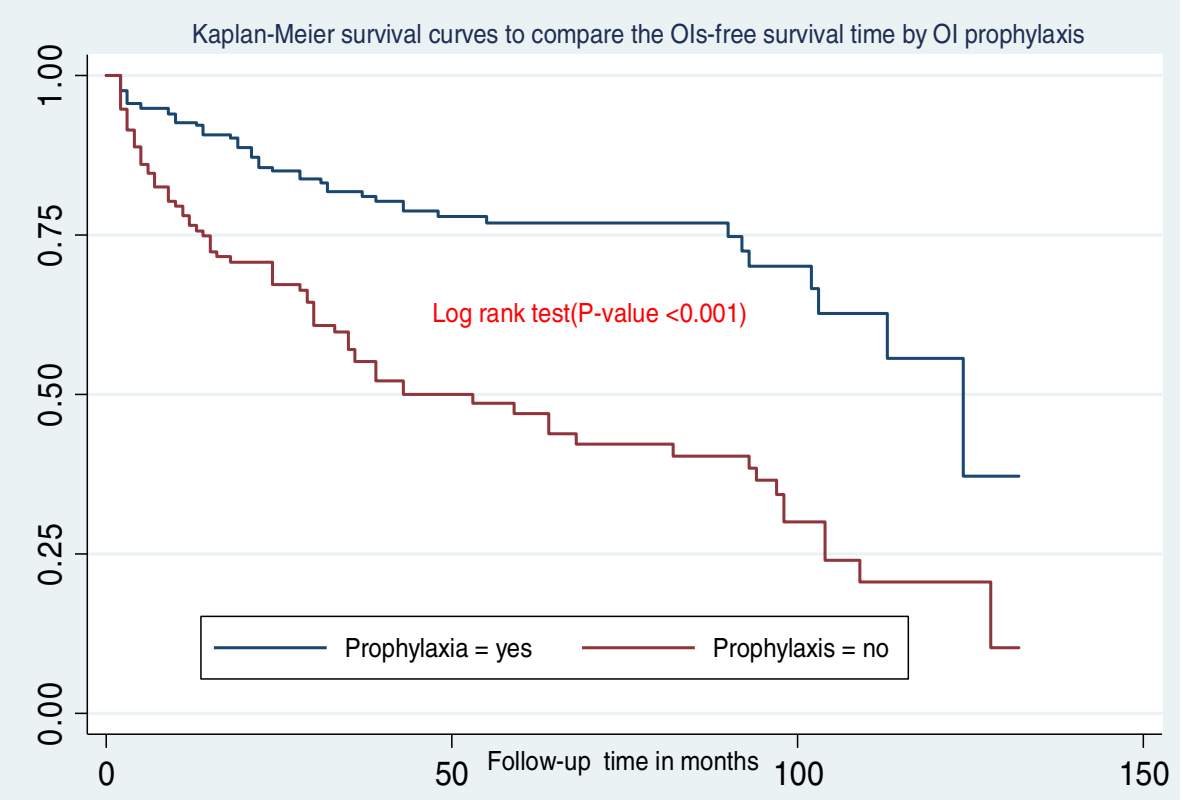

Fig. 5 Kaplan-Meier survival curves to compare the Ols-free survival time of HIV-infected children on ART with different categories of OI prophylaxis at Debre-Markos Referral Hospital from 2005 to March 2019 
Table 3 The bi-variable and multivariable Cox-regression analysis of the predictors of Ols among HIV-children on ART at DebreMarkos Referral Hospital, Northwest Ethiopia from January 1, 2005 to March 31, 2019 ( $N=408)$

\begin{tabular}{|c|c|c|c|c|}
\hline Variables & Events & Censored & CHR $(95 \% \mathrm{Cl})$ & AHR $(95 \% \mathrm{Cl})$ \\
\hline \multicolumn{5}{|l|}{ Age (years) } \\
\hline $0-4$ years & 36 & 86 & 1 & 1 \\
\hline $5-9$ years & 63 & 112 & $1.5(0.98,2.3)$ & $1.2(0.8,1.9)$ \\
\hline 10-14 years & 30 & 81 & $1.7(1.03,2.9)$ & $1.4(0.8,2.4)$ \\
\hline \multicolumn{5}{|l|}{ Current status of parents } \\
\hline Both alive & 59 & 160 & 1 & 1 \\
\hline One or both dead & 70 & 119 & $1.3(0.9,1.8)$ & $1.0(0.7,1.5)$ \\
\hline \multicolumn{5}{|l|}{ History of Ols } \\
\hline No & 45 & 148 & 1 & 1 \\
\hline Yes & 84 & 131 & $1.8(1.3,2.6)$ & $1.2(0.8,1.83)$ \\
\hline \multicolumn{5}{|l|}{ Weight for age Z-score } \\
\hline Normal weight & 55 & 152 & 1 & 1 \\
\hline underweight & 74 & 127 & $1.4(1.0,2.0)$ & $1.1(0.7,1.6)$ \\
\hline \multicolumn{5}{|l|}{ Height for age Z-score } \\
\hline Normal & 56 & 141 & 1 & 1 \\
\hline Stunted & 73 & 138 & $1.3(0.9,1.9)$ & $0.8(0.5,1.1)$ \\
\hline \multicolumn{5}{|l|}{ WHO clinical stage } \\
\hline Stage | and || & 41 & 176 & 1 & 1 \\
\hline Stage III and IV & 88 & 103 & $2.9(2.0,4.1)$ & $1.8(1.2,2.7)^{\mathrm{a}}$ \\
\hline \multicolumn{5}{|l|}{ CD4 counts or $\%$} \\
\hline Above the threshold & 60 & 217 & 1 & 1 \\
\hline Below the thresheold & 69 & 62 & $3.3(2.3,4.6)$ & $1.7(1.1,2.6)^{a}$ \\
\hline \multicolumn{5}{|l|}{ Hgb level } \\
\hline$\geq 10 \mathrm{~g} / \mathrm{dl}$ & 109 & 257 & 1 & 1 \\
\hline$<10 \mathrm{~g} / \mathrm{dl}$ & 20 & 22 & $1.7(1.1,2.8)$ & $1.0(0.6,1.7)$ \\
\hline \multicolumn{5}{|l|}{ Ever taking IPT } \\
\hline Yes & 64 & 162 & 1 & 1 \\
\hline No & 65 & 117 & $1.9(1.3,2.7)$ & $1.2(0.8,1.7)$ \\
\hline \multicolumn{5}{|l|}{ ART adherence } \\
\hline Good & 65 & 252 & 1 & 1 \\
\hline Fair/poor & 64 & 27 & $3.7(2.6,5.2)$ & $2.6(1.8-3.8)^{a}$ \\
\hline \multicolumn{5}{|l|}{ Past OI prophylaxis } \\
\hline Yes & 51 & 204 & 1 & 1 \\
\hline No & 78 & 75 & $2.8(2.0,4.0)$ & $1.6(1.1,2.4)^{\mathrm{a}}$ \\
\hline
\end{tabular}

significant predictors

among HIV-infected individuals [32].However, studies reported from Latin America [16, 17, 29] revealed that bacterial pneumonia is the most commonly diagnosed OI [33, 34]. A study done in India illustrated that pulmonary TB was the most common opportunistic infection and accounted for $26 \%$ of all OI cases [35]. PLHIV are 20 to 37 times more likely to develop TB as compared to the general population [18]. Besides, Cryptococcal meningitis accounted for $5.7 \%$ of OIs among HIV-infected children on ART at Debre Markos Referral Hospital. This is also an important finding since Cryptococcus neoformans is not a common cause of meningitis in children.

In this study, children who started ART as WHO clinical stage III and IV were more likely to develop OIs as compared to those children who started ART as WHO stage I and II. This finding aligns with studies done in India [36, 37], and Asia [21]. OIs tend increase in number and severity in alignment with WHO clinical disease 
staging [36]. WHO clinical stages and OIs have a positive association [37], such that HIV-infected individuals with WHO clinical stage III and IV often exhibit severe immune deficiency [38]. The level of immunity determines the occurrence and type of OIs [18]. Therefore, as the WHO clinical stage becomes more advanced the occurrence and recurrence of OIs also increase. The most serious and life threatening OIs become more common among HIV-infected peoples with stage III and IV.

This study also found that ART drug adherence is an important predictor for OIs. Children who had "fair or poor" ART drug adherence were more likely to develop OIs as compared to those who had good ART drug adherence. A study conducted in Cameron found that HIV-infected patients who were not adhered to the ART therapy were more prone to develop OIs. This study also documented that OIs significantly increased the risk of non-adherence [39].

HIV-infected children with CD4 count or \% below the threshold at the time of ART initiation were more likely to develop OIs as compared to those children with CD4 counts or \% above the threshold). A 10 year retrospective study conducted in Uganda [40] documented that the occurrence of OIs in patients with lower CD4 cell counts at ART start was significantly high. Similar studies conducted in India [32, 36], Latin America [29, 30, 41], and Asia [21] showed that low CD4 counts during ART enrollment significantly increased the risk of developing OIs. A study from the United States of America revealed that children who had a CD4 percentage of less than $15 \%$ at ART initiation were at higher risk of OIs compared to those children who had an on initiation CD4 percentage at or greater than 25\% [29]. CD4 cells are a type of white blood cells, which help to activate other white blood cells in the immune system. Therefore, any factors which reduce the number of CD4 cells will impair the immune system of HIV-infected children exposed to the development of OIs [42].

Lastly, this study found that the risk of developing OIs among HIV-infected children who took past OI prophylaxis was low as compared to those HIVinfected children who did not take past OI prophylaxis. Previous Ethiopian studies revealed that prophylaxis has a significant effect in reducing the occurrence of TB [43-45]. Another supportive finding was documented in Latin America [30]. Cotrimoxazole preventive therapy $(\mathrm{CPT})$ is a feasible, costeffective, and safe way intervention to reduce HIV/ AIDS related morbidities and mortalities associated with OIs [45]. Furthermore, the Ethiopian ART guideline recommends early initiation of CPT among HIVinfected children benefited for the prevention of OIs like pneumocystis pneumonia, bacterial infections, toxoplasmosis gondii, diarrhea and other protozoal infections; IPT to address latent TB, and fluconazole for prevention of fungal and cryptococcal infections [18].

\section{Limitations of the study}

The current study has some limitations, which must be considered before interpreting results. The data for this study was obtained from charts of HIV-infected children. Therefore, we were unable to get some variables including viral load, income, micronutrient deficiency, and immunization status of the children. At times, OIs might be underestimated due to excluded charts with incomplete data and unrecorded by health professions. Although the data are not always complete, the longitudinal data set may have corrected for some of these limitations.

\section{Conclusions}

In this study, the incidence rate of opportunistic infections among HIV-infected children remained high. Concerning predictors such as advanced disease stage (III and IV), CD4 count or \% below the threshold, "fair" or "poor" ART adherence, and not taking past OI prophylaxis were found to be significantly associated with OIs. Therefore, based on the above findings, we recommend consideration should be given to early screening and treatment of OIs. Besides, adherence support through phone calls and case managers could be strengthened. Furthermore, children presented with severe immunodeficiency and advanced disease stage during the ART initiation should be closely monitored and deeply investigated for the occurrence of OIs in each successive follow-up.

\section{Abbreviations}

AIDS: Acquired Immune Deficiency Syndrome; ART: Antiretroviral Therapy; AZT- 3TC-EFV: Zidovudine plus Lamivudine plus Efavirenz; AZT-3TC-

NVP: Zidovudine plus Lamivudine plus Nevirapine; CPT: Cotrimoxazole Preventive Therapy; HAART: Highly Active Antiretroviral Therapy; HAZ: Height for Age Z-score; Hgb: Hemoglobin; HIV: Human Immunodeficiency Virus; IPT: Isoniazid Preventive Therapy; Ols: Opportunistic Infections;

PMTCT: Prevention of Mother to Child Transmission; SSA: Sub-Saharan Africa; TB: Tuberculosis; WAZ: Weight for Age Z-score; WHO: World Health Organization; WHZ: Weight for Height Z score

\section{Acknowledgments}

The authors would like to acknowledge health care professionals working at the ART clinic of Debre Markos Referral Hospital for their kindness and valuable support during data collection and chart retrieval. The authors also extend their special thanks for both data collectors and supervisor.

\section{Authors' contributions}

MWM: conception of the research idea, design, data collection, analysis, interpretation, and initial manuscript write-up. MTG, AD, YTH, BT, PP, and AA: data collection, analysis and interpretation, and manuscript edition. All authors have read and approved the final manuscript.

Funding

Not applicable. 


\section{Availability of data and materials}

Data will be available upon request of the corresponding author.

\section{Ethics approval and consent to participate}

Ethical clearance was secured from an Institutional Review Committee of Debre Markos University, College of Health Sciences. In addition, a permission letter was written from the hospital general manager and HIV care clinic focal person to use the records of HIV-infected children. We conducted this study by reviewing existing medical records of HIV-infected children, therefore, informed oral or written consents from the parents or guardians were not feasible. The Ethics committee formally waived the consent. Patient's confidentiality was maintained by coding and locking all collected data in a separate room before data entry. After entry, all data were locked by password, names and unique ART numbers were not included in the data collection format and the data were not disclosed to any person other than the principal investigator.

\section{Consent for publication}

Not applicable.

\section{Competing interests}

The authors declare that they have no competing interests.

\section{Author details}

'Debre Markos Referral Hospital, P.O. Box 269, Debre Markos, Ethiopia. ${ }^{2}$ College of Health Science, Debre Markos University, Debre Markos, Ethiopia. ${ }^{3}$ College of Nursing, University of Saskatchewan, Saskatoon, Canada. ${ }^{4}$ School of Life Sciences and Bioengineering, Nelson Mandela African Institute of Science and Technology, Arusha, Tanzania. ${ }^{5}$ Faculty of Health, University of Technology Sydney, Sydney, Australia.

Received: 27 August 2019 Accepted: 7 January 2020

Published online: 16 January 2020

\section{References}

1. Gayle HD, Hill GL. Global impact of human immunodeficiency virus and AIDS. Clin Microbiol Rev. 2001;14(2):327-35.

2. UNIAS: Global HIV \& AIDS statistics - 2019 fact sheet available at https:// www.unaids.org/en/resources/fact-sheet. ; 2019.

3. UNAIDS. Fact sheet. Available from http://www.unaids.org/en/media/ unaids/contentassets/documents/factsheet/2014/20140716_FactSheet_en. pdf; 2014. p. 1-6.

4. Office FHAPaC: HIV Prevention in Ethiopia National Road Map2018-2020 Available from https://ethiopia.unfpa.org/sites/default/files/pub-pdf/HIV\%2 OPrevention\%20in\%20Ethiopia\%20National\%20Road\%20Map\%202018\%2 0-\%202020\%20FINAL FINAL.pdf; 2018.

5. Centers for Disease Control and Prevention (CDC): AIDS and Opportunistic Infections Available at https:/www.cdc.gov/hiv/basics/livingwithhiv/ opportunisticinfections.html. 2018.

6. World Health Organization: Global health sector strategy on HIV, 2016-2021 Available at https://www.who.int/news-room/fact-sheets/detail/hiv-aids; 2019

7. Kharsany AB, Karim QA. HIV infection and AIDS in sub-Saharan Africa: current status, challenges and opportunities. Open AIDS J. 2016;10:34-48.

8. Low A, Gavriilidis G, Larke N, BL MR, Drouin O, Stover J, Muhe L, Easterbrook $P$. Incidence of opportunistic infections and the impact of antiretroviral therapy among HIV-infected adults in Low- and middle-income countries: a systematic review and meta-analysis. Clin Infect Dis. 2016;62(12):1595-603.

9. Modi S, Chiu A, Ng'eno B, Kellerman SE, Sugandhi N, Muhe L. Understanding the contribution of common childhood illnesses and opportunistic infections to morbidity and mortality in children living with HIV in resource-limited settings. Aids. 2013;27(0 2):S159-67.

10. Candiani TM, Pinto J, Cardoso CA, Carvalho IR, Dias AC, Carneiro M, Goulart EA. Impact of highly active antiretroviral therapy (HAART) on the incidence of opportunistic infections, hospitalizations and mortality among children and adolescents living with HIV/AIDS in Belo Horizonte, Minas Gerais state, Brazil. Cad Saude Publica. 2007;23(Suppl 3):S414-23.

11. Haileamlak A, Hagos T, Abebe W, Abraham L, Asefa H, Teklu AM. Predictors of hospitalization among children on ART in Ethiopia: a cohort study. Ethiop J Health Sci. 2017;27(Suppl 1):53-62.
12. Kaplan JE, Hu DJ, Holmes KK, Jaffe HW, Masur H, De Cock KM. Preventing opportunistic infections in human immunodeficiency virus-infected persons: implications for the developing world. Am J Trop Med Hyg. 1996;55(1):1-11.

13. Mermin J, Were W, Ekwaru JP, Moore D, Downing R, Behumbiize P, Lule JR, Coutinho A, Tappero J, Bunnell R. Mortality in HIV-infected Ugandan adults receiving antiretroviral treatment and survival of their HIV-uninfected children: a prospective cohort study. Lancet. 2008;371(9614):752-9.

14. Chaisson RE, Moore RD. Prevention of opportunistic infections in the era of improved antiretroviral therapy. J Acquir Immune Defic Syndr Hum Retrovirol. 1997;16:S14-22.

15. Sisay MM, Ayele TA, Gelaw YA, Tsegaye AT, Gelaye KA, Melak MF. Incidence and risk factors of first-line antiretroviral treatment failure among human immunodeficiency virus-infected children in Amhara regional state, Ethiopia: a retrospective follow-up study. BMJ Open. 2018;8(4):e019181.

16. Alarcon JO, Freimanis-Hance L, Krauss M, Reyes MF, Cardoso CA, MussiPinhata MM, Cardoso E, Hazra R. Opportunistic and other infections in HIVinfected children in Latin America compared to a similar cohort in the United States. AIDS Res Hum Retrovir. 2012;28(3):282-8.

17. Gona P, Van Dyke RB, Williams PL, Dankner WM, Chernoff MC, Nachman SA, Seage GR. Incidence of opportunistic and other infections in HIV-infected children in the HAART era. Jama. 2006;296(3):292-300.

18. The Ethiopian Fedral Mlinistry of Health. National ART guidlines for prevention, care and treatment: Ministry of health Ethiopia; 2017.

19. Federal Ministry of Health Abuja - Nigeria: National guidelines for HIV and AIDS treatment and care in adolescents and adults Available from https:// www.who.int/hiv/pub/guidelines/nigeria_art.pdf; 2010.

20. UNAIDS: Ethiopia HIV Epidemic Available from http://www.unaidsrstesa.org/ wp-content/uploads/2015/05/UNAids-Profile-Ethiopia.pdf 2014.

21. Prasitsuebsai W, Kariminia A, Puthanakit T, Lumbiganon P, Hansudewechakul R, Moy FS, Law M, Kumarasamy N, Razali K, Sirisanthana V. Impact of antiretroviral therapy on opportunistic infections of HIV-infected children in the TREAT Asia pediatric HIV observational database. Pediatr Infect Dis J. 2014;33(7):747.

22. Central Statistical Authority. 2007 population and housing census of Ethiopia. Addis Ababa; 2012.

23. World Health Organization. Antiretroviral therapy of HIV infection in infants and children: towards universal access: recommendations for a public health approach-2010 revision: World Health Organization; 2010.

24. World Health Organization: WHO Child Growth Standards Available at http://www.who.int/childgrowth/standards/Technical_report.pdf. 2006.

25. Turck D, Michaelsen KF, Shamir R, Braegger C, Campoy C, Colomb V, Decsi T, Domellöf M, Fewtrell M, Kolacek S. World health organization 2006 child growth standards and 2007 growth reference charts: a discussion paper by the committee on nutrition of the European society for pediatric gastroenterology, hepatology, and nutrition. J Pediatr Gastroenterol Nutr. 2013;57(2):258-64.

26. WHO: WHO ANTIRETROVIRAL THERAPY FOR HIV INFECTION IN INFANTS AND CHILDREN: TOWARDS UNIVERSAL ACCESS Recommendations for a public health approach. HIV/AIDS Programme: 2010.

27. Bursac Z, Gauss CH, Williams DK, Hosmer DW. Purposeful selection of variables in logistic regression. Source Code Biol Med. 2008;3:17.

28. Hosmer DW Jr, Lemeshow S, Sturdivant RX. Applied logistic regression, vol. 398: Wiley; 2013.

29. Ylitalo N, Brogly S, Hughes MD, Nachman S, Dankner W, Van Dyke R, Seage GR 3rd. Risk factors for opportunistic illnesses in children with human immunodeficiency virus in the era of highly active antiretroviral therapy. Arch Pediatr Adolesc Med. 2006;160(8):778-87.

30. Nesheim SR, Kapogiannis BG, Soe MM, Sullivan KM, Abrams E, Farley J, Palumbo P, Koenig LJ, Bulterys M. Trends in opportunistic infections in the pre- and post-highly active antiretroviral therapy eras among HIV-infected children in the perinatal AIDS collaborative transmission study, 1986-2004. Pediatrics. 2007;120(1):100-9.

31. lacob SA, lacob DG, Jugulete G. Improving the adherence to antiretroviral therapy, a difficult but essential task for a successful hiv treatment-clinical points of view and practical considerations. Front Pharmacol. 2017;8:831.

32. Borle M, Sunkoj Y. Opportunistic Infection among HIV Infected Children and Their CD4 Cell Correlates. IOSR J Dent Med Sci. 2016;15(3).

33. Federal Ministry of Health of Ethiopia: Implementation Guideline for TB/HIV Collaborative Activities in Ethiopia Available at http://www.who.int/hiv/pub/ guidelines/ethiopia.pdf; 2007.

34. Lawn SD, Meintjes G, Mcllleron H, Harries AD, Wood R. Management of HIVassociated tuberculosis in resource-limited settings: a state-of-the-art review. BMC Med. 2013;11(1):253. 
35. Ravichandra KR. Sunil Agarwalla: Opportunistic infections in HIV infected children and its correlation with CD4 count. Int J Contemp Pediatr. 2017;4.

36. Dhaka G, Sherwal BL, Saxena S, Rai Y, Chandra J. Current trends in opportunistic infections in children living with HIV/AIDS in a tertiary care hospital in northern India. Indian J Sex Transm Dis AIDS. 2017;38(2):142-6.

37. NGH KBB, Patil RT. Prevalence and risk factors for opportunistic infections in HIV patients who developed adverse drug reactions (ADRs) to antiretroviral therapy (ART) in a tertiary-care teaching hospital. Nat J Physiol Pharm Pharmacol. 2015;5(3).

38. World Health Organization: WHO case definitions of HIV for surveillance and revised clinical staging and immunological classification of HIV-related disease in adults and children; 2007.

39. Fonsah JY, Njamnshi AK, Kouanfack C, Qiu F, Njamnshi DM, Tagny CT, Nchindap E, Kenmogne L, Mbanya D, Heaton R, et al. Adherence to antiretroviral therapy (ART) in Yaounde-Cameroon: association with opportunistic infections, depression, ART regimen and side effects. PLoS One. 2017;12(1):e0170893.

40. Weissberg D, Mubiru F, Kambugu A, Fehr J, Kiragga A, von Braun A, Baumann A, Kaelin M, Sekaggya-Wiltshire C, Kamya M. Ten years of antiretroviral therapy: Incidences, patterns and risk factors of opportunistic infections in an urban Ugandan cohort. PloS one. 2018;13(11):e0206796. https://doi.org/10.1371/journal.pone.0206796.

41. Ledergerber B, Egger M, Erard V, Weber R, Hirschel B, Furrer H, Battegay M, Vernazza P, Bernasconi E, Opravil M. AIDS-related opportunistic illnesses occurring after initiation of potent antiretroviral therapy: the Swiss HIV cohort study. Jama. 1999;282(23):2220-6

42. de Arruda Caceres N, Vieira C, Vieira IF, Figueiredo V, Monteleone LJMN, Bonafe S. Opportunistic Infections in Aids Patients. iMedPub J. 2015;5.

43. Alemu YM, Andargie G, Gebeye E. High incidence of tuberculosis in the absence of isoniazid and Cotrimoxazole preventive therapy in children living with HIV in northern Ethiopia: a retrospective follow-up study. PLoS One. 2016;11(4):e0152941.

44. Ayalaw SG, Alene KA, Adane AA. Incidence and Predictors of Tuberculosis among HIV Positive Children at University of Gondar Referral Hospital, Northwest Ethiopia: A Retrospective Follow-Up Study. Int Sch Res Notices. 2015;2015:307810.

45. Sisay M, Bute D, Edessa D, Mengistu G, Amare F, Gashaw T, Bihonegn T. Appropriateness of Cotrimoxazole prophylactic therapy among HIV/AIDS patients in public hospitals in eastern Ethiopia: a retrospective evaluation of clinical practice. Front Pharmacol. 2018;9.

\section{Publisher's Note}

Springer Nature remains neutral with regard to jurisdictional claims in published maps and institutional affiliations.

Ready to submit your research? Choose BMC and benefit from:

- fast, convenient online submission

- thorough peer review by experienced researchers in your field

- rapid publication on acceptance

- support for research data, including large and complex data types

- gold Open Access which fosters wider collaboration and increased citations

- maximum visibility for your research: over $100 \mathrm{M}$ website views per year

At $\mathrm{BMC}$, research is always in progress.

Learn more biomedcentral.com/submissions 